\title{
Association of Low Perceived Social Support with Emotional Disturbances among Undergraduate Students of Faculty of Nursing in Malaysia
}

\author{
Ali Sabri Radeef FIBMS Psych ${ }^{1}$, Ghasak Ghazi Faisal ${ }^{2 *}$, FIBMS path \\ ${ }^{1}$ Department of Psychiatry, Kulliyyah (Faculty) of Medicine, International Islamic University Malaysia \\ ${ }^{2}$ Department of Fundamental Dental and Medical Sciences, Kulliyyah (Faculty) of Dentistry, International Islamic University \\ Malaysia
}

\author{
Article History \\ Received: 02.10.2020 \\ Accepted: 22.10 .2020 \\ Published: 30.10 .2020 \\ Journal homepage:
}

https://www.easpublisher.com/easjpbs

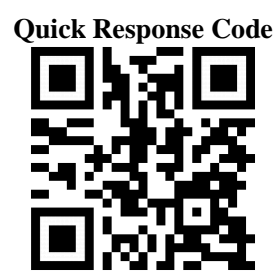

Abstract: Introduction: Social support plays an important role in maintaining psychological well-being of students. Nursing students are subjected to a variety of stressors during their study and level of perceived social support is one of these factors which may precipitate to emotional disturbances in the form of depression, anxiety and stress which may affect students' academic performance, physical health and quality of life. Therefore, this study aimed to assess the social support among nursing students and its association with depression, anxiety and stress symptoms. Methodology: A sample of 174 nursing students from International Islamic University Malaysia participated in this study. Depression Anxiety, Stress Scale (DASS-21) was used to assess the emotional disturbances in the form of depression, anxiety and stress (DAS) symptoms. The multidimensional scale of perceived social support (MSPSS) was used to measures perceived social support. Results: The mean score of depression for all students was at mild level (11.47), mean anxiety score was at moderate level (14.77) while mean stress score was at normal level (14.76). Majority of nursing students scored high social support. No significant differences between the gender and age of students in relation to social support. The social support is negatively associated and correlated with depression among nursing students. Conclusion: Symptoms of depression, anxiety and stress are existed among nursing students which need to be early detected. The social support is negatively associated and correlated with depression among nursing students. No significant differences between the genders in relation to perceived social support.

Keywords: Emotional disturbances, social support, nursing students, Malaysia.

Copyright (C) 2020 The Author(s): This is an open-access article distributed under the terms of the Creative Commons Attribution 4.0 International License (CC BY-NC 4.0) which permits unrestricted use, distribution, and reproduction in any medium for non-commercial use provided the original author and source are credited.

\section{INTRODUCTION}

The definition of health in the Constitution of the World Health Organization: "Health is a state of complete physical, mental and social well-being and not merely the absence of disease or infirmity [1]", therefore maintaining psychological health and wellbeing are essential in achieving physical health and contribute to satisfaction in life. Undergraduate students are undergoing different levels of stressors during various stages of their studies [2,3].

Higher education is considered as a stressful period in students' life which they have to cope with since they are facing a variety of demands such as living away from their families, a heavily loaded curriculum, and inefficiency in both mentor- mentee and health education programs. Social support plays an important role in maintaining psychological well-being of the undergraduate students. Nursing students are subjected to a variety of stressors during their study and level of perceived social support is one of these factors which may precipitate to emotional disturbances in the form of depression, anxiety and stress which may affect students' academic performance, physical health and quality of life.

Social support refers to the function and quality of social relationships, such as perceived availability of help or support actually received. It occurs through an interactive process and can be related to altruism, a sense of obligation, and the perception of reciprocity [4].

Social support can come from a variety of sources, including (but not limited to): family, friends, romantic partners, pets, community ties, and coworkers [5].

Perceived support refers to a recipient's subjective judgment that providers will offer (or have offered) effective help during times of need. Received support (also called enacted support) refers to specific 
supportive actions (e.g., advice or reassurance) offered by providers during times of need [6].

Perceived social support might indirectly have an effect on psychological well-being through mediating role of academic motivation [7].

The Bachelor of nursing is an undergraduate degree programme offered by Kulliyyah (faculty) of nursing that lasts four (4) years duration and incorporates a substantial amount of guided clinical practice in hospitals and health care settings as well as a range of campus-based theoretical and clinical-based teaching/learning activities. The aim is to acquire the scientific knowledge and psychomotor skill necessary for future clinical training. Presence of stressors during education can affect the students in broad aspects such as their learning process and functionality, mental and physical health. This will make them more vulnerable to emotional disturbances such as stress, anxiety and depression [8]. Depression is defined by the American Psychiatric Association in the Diagnostic and Statistical Manual of Mental Disorders-5 (DSM-5) as a disorder that is characterized by persistent mood and /or markedly loss of interest in all activities in addition to at least four other symptoms within a duration of at least two weeks, these symptoms include, significant weight loss/weight gain, disturbed sleep, diminished concentration, fatigability, psychomotor agitation or retardation, feeling of worthlessness or inappropriate guilt, thoughts of death or recurrent suicidal ideation[9]. Anxiety is a condition that is characterized by intense feeling of dread, worries and apprehension accompanied by somatic symptoms that indicate a hyperactive autonomic nervous system; also it impairs cognition and may produce distortions of perception [10]. Stress can be defined as the physiological and psychological response to events that are appraised as threatening or challenging that require adjustment [11].

This study aimed to assess the social support among nursing students and its association with depression, anxiety and stress symptoms. The results of this study may aid in designing apposite intervention strategies and proper revision in nursing curriculum to enhance the students' learning skills and assure sustainability of their psychological wellbeing.

\section{METHODOLOGY}

This is a cross sectional study conducted among undergraduate nursing students from Kulliyyah (faculty) of Nursing, International Islamic University Malaysia (IIUM). A research grant sponsored by IIUM was obtained for conducting this research and ethical approval was obtained from International Islamic University Malaysia Research Ethical Committee prior to conducting the study. The participation was entirely on a voluntary basis and students were insured about confidentiality.
Consent was obtained from the students. The study was conducted in middle of the course before the examination period so as to minimize the extra stress symptoms. The inclusion criteria were students who agreed to participate in the study and the students should be registered as undergraduate students of Kulliyyah of Nursing, IIUM. Students who fail to give consent, and those who were not conversant in English were excluded from the study. The socio-demographic characteristics of the participants were obtained; the gathered information was about the nationality, age, marital status, gender, year of study, accommodation during study and household income.

The psychological well-being was assessed by using the Depression Anxiety, Stress Scale (DASS-21) which is a short version, self- rated questionnaire that is designed to assess the severity of the symptoms of depression, anxiety and stress; it consists of statements referring to the past week. Each item is scored on a 4point scale $(0=$ Did not apply to me at all, $1=$ Applied to me to some degree, or some of the time, $2=$ Applied to me to a considerable degree, or a good part of time, and 3 = Applied to me very much or most of the time) 12. Subjects were asked to use 4-point severity/frequency scales to rate the extent to which they have experienced each state over the past week. Scores for depression, anxiety and stress are calculated by summing the scores for the relevant items. Each subscale was categorized into normal, mild, moderate, severe and extremely severe.

The multidimensional scale of perceived social support (MSPSS) was developed by Zimet et al. [13] as a self-administered tool that measures perceived social support. It addresses the subjective assessment of social support adequacy. It was designed to assess the perception of social support adequacy from three different sources: Family, Friends and Significant Others. The MSPSS contains 12 items, therefore it is simple to use and can be quickly administered and scored. Items Are scored on a7-point rating scale ranging from 1 (very strongly disagree to 7 (very strongly agree) with possible scores ranging from 12 to 84. The reliability, validity and factor structure of the MSPSS have been demonstrated across a number of different samples [14, 15].

\section{STATISTICAL ANALYSIS}

We used the statistical package for social science program, version 22.0 (SPSS 22.0) for analyzing the data. The analysis of qualitative variables such as age group, gender, nationality, monthly household income, marital status, year of study and type of accommodation were presented in number and percentage. Mann-Whitney U test and Kruskal-Wallis test were used to determine the association of important socio-demographic characteristics and emotional disturbances in the form of DAS symptoms with the perceived social support among the students. The 
relationship between perceived social support and was evaluated using Spearman's rho. P values less than 0.05 was considered statistically significant

\section{RESULTS}

A total of 174 nursing students participated in this study. Regarding the distribution of students; 47, 30, 55 and 42 students participated from year1, year2, year3 and year4 respectively. The majority of the students were females, aged above 22 years, Malaysian, single, living in the hostel with low monthly household income ranged $(\leq 1500$ Ringgit Malaysia).
Mean scores for depression, anxiety and stress symptoms were $11.47,14.77$ and 14.76 respectively, while the mean score of perceived social support was 5.4.

Although the mean score for perceived social support was slightly higher among female than male participants, the results were not statistically significant.

Year1 students had higher mean score of perceived social support compared to other years $(\mathrm{P}=0.016)$, while age of students, accommodation, household incomes were not associated with perceived social support (Table 1).

Table-1: Factors determining perceived social support among undergraduate students of Kulliyyah (faculty) of Nursing:

\begin{tabular}{|c|c|c|c|}
\hline & $\begin{array}{c}\text { Total } \\
\text { No. }(\%)\end{array}$ & Mean perceived social support Level & P Value \\
\hline \multicolumn{4}{|l|}{ Gender } \\
\hline Male & $31(17.8)$ & 5.3 & \\
\hline Female & $143(82.2)$ & 5.5 & 0.47 \\
\hline \multicolumn{4}{|l|}{ Age } \\
\hline$\leq 22$ & $79(45.4)$ & 5.2 & \\
\hline$>22$ & $95(54.6)$ & 5.4 & 0.36 \\
\hline \multicolumn{4}{|l|}{ Household income } \\
\hline$\leq \mathrm{RM} 1500$ & $82(47.1)$ & 5.4 & 0.81 \\
\hline RM 1501-5000 & $62(35.7)$ & 5.5 & \\
\hline >RM 5000 & $30(17.2)$ & 5.5 & \\
\hline \multicolumn{4}{|l|}{ Year of study } \\
\hline Year 1 & $47(27.1)$ & 5.7 & \\
\hline Year 2 & $30(17.2)$ & 5.4 & 0.016 \\
\hline Year 3 & $55(31.6)$ & 5.1 & \\
\hline Year 4 & $42(24.1)$ & 5.6 & \\
\hline \multicolumn{4}{|l|}{ Accommodation } \\
\hline Hostel & $169(97.1)$ & 5.4 & 0.87 \\
\hline Non-Hostel & $5(2.9)$ & 5.5 & \\
\hline
\end{tabular}

Data was analyzed using Mann-Whitney U test for two independent variables and Kruskal-Wallis one-way analysis of variance for more than two independent variables. P values less than 0.05 was considered statistically significant. Data was presented as mean

Regarding the level of perceived social support, this study showed that $8 \%$ of the students had low level while $20.7 \%$ had moderate and $71.3 \%$ showed high perceived social support. Although students with low perceived social support had higher mean score of depression, anxiety and stress symptoms, it was only statically significant with depression symptoms $(\mathrm{p}=0.000)($ table 2$)$.

Table-2: Level of social support in relation to mean score of depression, anxiety and stress symptoms

\begin{tabular}{|c|c|c|c|c|c|c|c|}
\hline Perceived social support & $\begin{array}{c}\text { Total } \\
\text { No. (\%) }\end{array}$ & Mean Depressive Level & P Value & $\begin{array}{c}\text { Mean } \\
\text { Anxiety } \\
\text { Level }\end{array}$ & P Value & $\begin{array}{c}\text { Mean } \\
\text { Stress } \\
\text { Level }\end{array}$ & P Value \\
\hline Low & $14(8.0)$ & 19.29 & & 18.57 & & 19.43 & \\
\hline Moderate & $36(20.7)$ & 12.56 & 0.000 & 13.67 & 0.221 & 14.44 & 0.089 \\
\hline High & $124(71.3)$ & 10.27 & & 14.66 & & 14.32 & \\
\hline Total & $174(100)$ & 11.47 & & 14.77 & & 14.76 & \\
\hline
\end{tabular}

Data was analyzed using Kruskal-Wallis one-way analysis of variance. P values less than 0.05 was considered statistically significant. Data was presented as mean.

There was a negative correlation between perceived social support and depression among nursing students $(r=-$ $0.54, \mathrm{p}<0.00)$ (Table 3). 
Table-3: Correlation between perceived social support and depression

\begin{tabular}{|c|c|c|c|c|}
\hline & & & Mean perceived social support & Depression \\
\hline \multirow[t]{6}{*}{ Spearman's rho } & \multirow[t]{3}{*}{$\begin{array}{l}\text { Mean perceived } \\
\text { social support }\end{array}$} & $\begin{array}{l}\text { Correlation } \\
\text { Coefficient }\end{array}$ & 1.000 & $-.313^{* *}$ \\
\hline & & Sig. (2-tailed) & . & .000 \\
\hline & & $\mathrm{N}$ & 174 & 174 \\
\hline & \multirow[t]{3}{*}{ Depression } & $\begin{array}{l}\text { Correlation } \\
\text { Coefficient }\end{array}$ & $-.313^{* *}$ & 1.000 \\
\hline & & Sig. (2-tailed) & .000 & \\
\hline & & $\mathrm{N}$ & 174 & 174 \\
\hline
\end{tabular}

\section{DISCUSSION}

In this study, the mean score of depression for all students was at mild level (11.47), mean anxiety score was at moderate level (14.77) while mean stress score was at normal level (14.76) which was slightly higher than mean scores in a previous study among dental students in Malaysia in which the mean scores were 10.3, 11.2, and 14.3 for depression, anxiety and stress respectively[16] and another study in Malaysia among 506 students from Social and Political Sciences, Human Medicine and Veterinary and Basic Sciences and Engineering in which the mean scores of depression for all students were found to be 11.04, 11.77 and 13.85 respectively[17]. however, our results were less than other study among science students in Malaysia, in which the mean scores of depression, anxiety and stress were $12.5,15.9$ and 16.6 respectively [18], and also lower than other study conducted among nursing students in Sri Lanka which showed that the mean scores for depression, anxiety and stress were 17.8, 11.1 and 18.9 respectively [19]. The reasons behind getting different means scores/severity of depression, stress and anxiety than previous studies may be due to the type of course studied, sample size, stages of study, difficulty in curriculum and cultural differences.

The mean score of perceived social support was 5.4 which can be considered as high level of social support and this is closely similar to a previous study in Malaysia in which the mean score was 5,3[20].

The majority of students in this study $(71.3 \%)$ scored high on the perceived social support while $20.7 \%$ had moderate and $8 \%$ of the students had had scored low on perceived social support, this is closely similar to a previous study among undergraduate students in Malaysia in which the majority of students scored high and $5 \%$ scored low on the perceived social support [21].

There was no significant gender difference for perceived social support among male and female students and this is similar to the findings in previous studies [22, 23].

In this study, the perceived social support was negatively associated and correlated with depression among nursing students and this is consistent with previous studies done among university students [24, 25].

Results of this study provide an evidence for relation between perceived social support and depression among university students that requires empowering the social support that students received in order to reduce the level of emotional disturbances among the students.

\section{CONCLUSIONS}

Symptoms of depression, anxiety and stress are existed among nursing students which need to be early detected. The social support is negatively associated and correlated with depression among nursing students. No significant differences between the genders in relation to perceived social support.

\section{ACKNOWLEDGMENT}

We would like to express our appreciation to all nursing students for their participation and consent. Also to International Islamic University Malaysia for funding this project (Grant number (PRIGS 18-0300030)

\section{Conflict of Interest Statement}

The authors declare no conflict of interest

\section{REFERENCES}

1. Mental health action plan 2013-2020. (2013). World Health Organization 2013. http://apps. who.int/iris/bitstream/10665/89966/1/9 789241506021_eng.pdf?ua=1

2. Abdulghani, H.M., AlKanhal, A.A., Mahmoud, E.S. (2011). Stress and Its Effects on Medical Students: A Cross-sectional Study at a College of Medicine in Saudi Arabia, J health popul nutr, 29(5): 516-522.

3. Yusoff, M.S., Abdul, Rahim, A.F., Yaacob, M.J. (2010). Prevalence and Sources of Stress among Universiti Sains Malaysia Medical Students, Malays J Med Sci, 17(1):30-7.

4. Schwarzer, R., Leppin, A. (1992). The possible impact of social ties and support on morbidity and mortality in the meaning and measurement of social support, Hemisphere, pp. 65-83. 
5. Taylor, S. E. (2011). Social Support: A Review. The Oxford Handbook of Health Psychology, New York, NY: Oxford University Press, 189214.

6. Gurung, R.A.R. (2006). Coping and Social Support, Health Psychology: A Cultural Approach, Belmont, CA: Thomson Wadsworth, 131-171.

7. Emadpoor, L., Lavasani, M.G., Shahcheraghi, S.M. (2016). Relationship between perceived social support and psychological well-being among students based on mediating role of academic motivation, International Journal of Mental Health and Addiction, 14(3):284-90.

8. Kumaraswamy, N. (2013). Academic stress, anxiety and depression among college students- A brief review, International Review of Social Sciences and Humanities, 5(1): 135-43.

9. American, P. A. (2013). Mood disorders. Diagnostic and Statistical Manual of Mental Disorders, $\left(5^{\text {th }}\right.$ edition). American Psychiatric Association. Washington, DC, 345-429.

10. Sadock, B.J., Sadock, V.A. (2005). Anxiety disorders. Kaplan and Sadock's Pocket handbook of clinical psychiatry, 4th Edn. Lippincott Williams \&Wikins. 11: 70-185.

11. Samuel, E., Wood, Ellen, G.W., \& Denise, B. (2004). Mastering the world of psychology. Health and stress. Person Education, Inc, 10: 286-311.

12. Lovibond, S.H., \& Lovibond, P.F. (1995). Manual for the Depression Anxiety Stress Scales. Sydney: $2^{\text {nd }}$. Edn. Psychology Foundation.

13. Zimet, G.D., Dahlem, N.W., Zimet, S.G., Farley, G.K. (1988). The multidimensional scale of perceived social support, J Personality Assess, 52:30-41.

14. Ng, C.G., Siddiq, A.A., Aida, S.A., Zainal, N.Z., Koh, O.H. (2010). Validation of the Malay version of the Multidimensional Scale of Perceived Social Support (MSPSS-M) among a group of medical students in Faculty of Medicine, University Malaya. Asian Journal of Psychiatry, 3(1):3-6.

15. Vaingankar, J.A., Abdin, E., Chong, S.A. (2012). Exploratory and confirmatory factor analyses of the Multidimensional Scale of Perceived Social Support in patients with schizophrenia, Comprehensive psychiatry, 53(3):286-91.
16. Radeef, A.S., Faisal, G.G. (2018). Stressors and Their Association with Symptoms of Depression, Anxiety and Stress in Dental Students, Makara Journal of Health Research, 22(2):1.

17. Shamsuddin, K., Fadzil, F., Ismail, W.S., Shah, S.A., Omar, K., Muhammad, N.A., Jaffar, A., Ismail, A., Mahadevan, R.(2013). Correlates of depression, anxiety and stress among Malaysian university students, Asian journal of psychiatry, 6(4):318-23.

18. Radeef, A.S., Faisal, G.G., Ali, S.M., Ismail, M.K. (2014). Source of stressors and emotional disturbances among undergraduate science students in Malaysia, International Journal of Medical Research \& Health Sciences, 3(2):40110.

19. Rathnayake, S., Ekanayaka, J. (2016). Depression, anxiety, and stress among undergraduate nursing students in a public university in Sri Lanka. International Journal of Caring Sciences, 9(3):1020-32.

20. Talwar, P., Rahman, M.F. (2013). Perceived social support among University students in Malaysia: A reliability study, Malaysian Journal of Psychiatry, 22(1).

21. Talwar, P., Kumaraswamy, N., AR, M.F. (2013). Perceived social support, stress and gender differences among university students: A cross sectional study, Malaysian Journal of Psychiatry, 22(2):42-9.

22. Tam, C.L., Lee, T.H., Har, W.M., Pook, W.L. (2011). Perceived social support and self-esteem towards gender roles: Contributing factors in adolescents. Asian Social Science, 7(8):49.

23. Malkoush, R. (2000). Social support and scholastic adjustment among students of the University of Jordan. Dirasat: Educational Sciences, 27(1), 161-172.

24. Bukhari, S.R., Afzal, F. (2017). Perceived social support predicts psychological problems among university students, The International Journal of Indian Psychology, 23;4(2):18-27.

25. Kugbey, N., Osei-Boadi, S., Atefoe, E.A. (2015). The Influence of Social Support on the Levels of Depression, Anxiety and Stress among Students in Ghana, Journal of Education and Practice,6(25):135-40. 